\title{
UTILIZAÇÃO DE CILINDROS DE AÇO RÁPIDO (HSS) NO LAMINADOR STECKEL DA APERAM
}

Arísio de Abreu Barbosa ' Flávio da Silva ${ }^{2}$

Luiz Otávio Torres Procópio ${ }^{3}$

\section{Resumo}

Este trabalho relata as principais ações implantadas para consolidar o uso de cilindros de trabalho em aço rápido no laminador Steckel da Aperam. Dentre elas podemos citar: melhoria do sistema de refrigeração dos cilindros, sistematização dos critérios de inspeção por Eddy Current e Ultrassom, adequação da coroa mecânica dos cilindros e disseminação dos cuidados durante a utilização dos mesmos. Todas essas ações associadas contribuíram para a consolidação da utilização desse tipo de cilindro, considerado hoje como estado da arte, dotando o Laminador Steckel com uma maior autonomia de laminação. Os resultados obtidos foram notórios, tais como: redução do número de trocas, redução do número de setups, aumento do índice de funcionamento da linha e rendimento físico, melhoria da qualidade superficial das tiras, diminuição de horas de máquina para retificação dos cilindros, etc.

Palavras-chave: Cilindros de trabalho; Laminador Steckel; Cilindros de aço rápido.

\section{USE OF HIGH SPEED STEEL WORK ROLLS (HSS) ON APERAM STECKEL MILL}

\begin{abstract}
This paper outlines the main actions taken to reinforce the decision to use HSS work rolls on the Aperam Steckel Mill. These are: work roll cooling improvements, systematically analyzing Eddy Current and Ultrasonic non destructive tests, mechanical adjustment of work roll crown and critically examining the rolling process. These actions applied together have contributed to the success of HSS rolls state of the art application, and provide the Steckel Mill with a much improved performance. Significant results have been achieved, such as: increasing of work roll change intervals, increasing of the available production time, a yield gain, a product quality improvement, less working hours needed for the roll grinding operation, etc.

Keywords: Work rolls; Steckel mill; High speed steel rolls.
\end{abstract}

'Mestre em Conformação Mecânica, Engenheiro de processo, Gerência da Laminação a Quente, Aperam, Timóteo, MG, Brasil. E-mail: arisio.barbosa@aperam.com

${ }^{2}$ Técnico em Metalurgia, Assistente Técnico, Gerência da Laminação a Quente, Aperam, Timóteo, MG, Brasil. E-mail: flavio.silva@aperam.com

${ }^{3}$ Engenheiro Metalúrgico, Gerente Executivo, Laminação a Quente, Aperam, Timóteo, MG, Brasil. E-mail: luiz-otavio.procopio@apeam.com 


\section{INTRODUÇÃO}

\section{I.I Motivação do Trabalho}

Cilindros de laminação sempre despertaram interesse no seu desenvolvimento e, sobretudo hoje em dia, muitos estudos estão sendo feitos para que essa ferramenta tenha um desempenho cada vez melhor, tanto em laminadores contínuos quanto em laminadores reversíveis como é o caso do laminador Steckel da Aperam. Isso se deve basicamente a três particularidades extremamente importantes no processo de laminação, a saber:

- É necessário interromper o processo produtivo para que eles sejam substituídos, afetando assim diretamente o índice de funcionamento da linha. Hoje são realizadas em média 200 trocas de cilindros de trabalho do Steckel por mês o equivalente a mais de 15 horas de linha parada;

- Os cilindros de trabalho fazem contato diretamente com o material laminado, logo, a qualidade superficial dos mesmos é de suma importância para a qualidade superficial da tira, principalmente no caso da Aperam onde 52\% do mix dos produtos são aços inoxidáveis;

- Por último, trata-se de um insumo de alto custo no processo de laminação a quente, perdendo apenas para energia elétrica e gás natural, utilizado nos fornos de reaquecimento de placas e nos fornos do Steckel [I].

No final da década de oitenta no Japão, e início da década de noventa na Europa, tentou-se utilizar cilindros de ferro fundido multicomponentes, conhecidos no mercado como cilindros de aço rápido, ou simplesmente HSS, nas últimas cadeiras dos laminadores contínuos. $O$ objetivo era substituir os cilindros de ferro fundido convencionais, ICDP (indefinit chill double poured), que apresentavam baixa resistência ao desgaste em relação aos cilindros de alto cromo já desenvolvidos para as primeiras cadeiras. Entretanto, devido à baixa resistência a trincas apresentada pelos cilindros HSS, os resultados dos testes nas últimas cadeiras foram catastróficos. Isto é, foram observados grandes lascamentos durante a laminação bem como perdas elevadas no processo de retificação para eliminação das trincas originadas durante $\circ$ trabalho, tornando inviável sua aplicação [2].
Apesar dos resultados obtidos pelos japoneses e europeus, a Aperam iniciou, em 2005, um grande desafio: desenvolver a aplicação de cilindros HSS no laminador Steckel, pois mesmo sendo um laminador de concepção diferente dos laminadores contínuos, possui características semelhantes às das últimas cadeiras de um laminador Tandem (F5, F6 e F7). Tudo isso motivado pela perspectiva de grandes ganhos prometidos pelos cilindros HSS em relação aos cilindros de ferro fundido convencionais.

\section{I.2 Objetivos}

Desenvolver a aplicação de cilindros de aço rápido no Laminador Steckel da Aperam com o intuito de aumentar o desempenho dos cilindros de trabalho, melhorar a qualidade superficial da tira laminada a quente $e$ reduzir a participação na formação do custo de produção.

\section{I.3 Revisão da Literatura}

\subsection{Constituição dos cilindros de trabalho}

As condições operacionais inerentes ao processo de laminação a quente mais os requisitos de qualidade requeridos pelo produto, exigem que os cilindros de trabalho tenham características antagônicas. É preciso aliar, em uma mesma peça, alta tenacidade e boa resistência ao desgaste. Sendo assim, os cilindros são fabricados geralmente com dois tipos de materiais diferentes. $O$ núcleo em ferro fundido nodular e a casca em ferro fundido indefinido ou ferro fundido branco multicomponente (Figura I). $\mathrm{O}$ material da casca é rico em carbonetos distribuídos em uma matriz martensítica, proporcionando uma alta resistência ao desgaste.

$\mathrm{Na}$ Tabela I temos a composição química típica dos materiais constituintes do núcleo (ferro fundido nodular) e da casca (ferro fundido de coquilhamento indefinido - ICDP e aço rápido - HSS).

\subsubsection{Características do cilindro de trabalho HSS em relação ao cilindro ICDP}

Ao comparar as propriedades mecânicas do cilindro HSS em relação ao cilindro ICDP (Tabela 2), percebe-se que todos os valores são maiores para o cilindro HSS. Mas nem todas elas são favoráveis ao processo de laminação,

Tabela I. Composição química típica e dureza dos materiais do núcleo e da casca dos cilindros de trabalho ICDP e HSS [3]

\begin{tabular}{|c|c|c|c|c|c|c|c|c|c|c|}
\hline & C & Si & Mn & $\mathbf{N i}$ & $\mathrm{Cr}$ & Mo & $\mathbf{w}$ & $\mathbf{V}$ & $\mathbf{N b}+\mathbf{T i}$ & HSc \\
\hline $\mathbf{F}^{\circ} \mathbf{F}^{\circ}$ & 3,00 & $\mathrm{I}, 75$ & 0,20 & 0,70 & 0,55 & 0,35 & & & & 33 \\
\hline Nodular & 3,60 & 2,95 & 0,80 & 2,00 & Max. & Max. & & & & 40 \\
\hline $\mathrm{F}^{\circ} \mathrm{F}^{\circ} \mathrm{ICDP}$ & $\begin{array}{l}3,00 \\
3,60\end{array}$ & $\begin{array}{l}0,65 \\
1,25\end{array}$ & $\begin{array}{l}0,45 \\
1,05\end{array}$ & $\begin{array}{l}4,10 \\
4,70\end{array}$ & $\begin{array}{l}1,40 \\
2,00\end{array}$ & $\begin{array}{l}0,25 \\
0,65\end{array}$ & $\begin{array}{l}\text { I,50 } \\
\text { Max. }\end{array}$ & $\begin{array}{l}1,50 \\
\text { Max. }\end{array}$ & $\begin{array}{l}3,00 \\
\text { Max. }\end{array}$ & $\begin{array}{l}72 \\
77\end{array}$ \\
\hline HSS & $\begin{array}{l}1,00 \\
2,50\end{array}$ & $\begin{array}{l}0,10 \\
1,50\end{array}$ & $\begin{array}{l}0,10 \\
1,00\end{array}$ & 2,00 & $\begin{array}{l}3,00 \\
8,00\end{array}$ & $\begin{array}{l}0,50 \\
2,50\end{array}$ & $\begin{array}{l}2,00 \\
6,00\end{array}$ & $\begin{array}{l}2,00 \\
6,00\end{array}$ & $\begin{array}{l}4,00 \\
\text { Max. }\end{array}$ & $\begin{array}{l}70 \\
82\end{array}$ \\
\hline
\end{tabular}




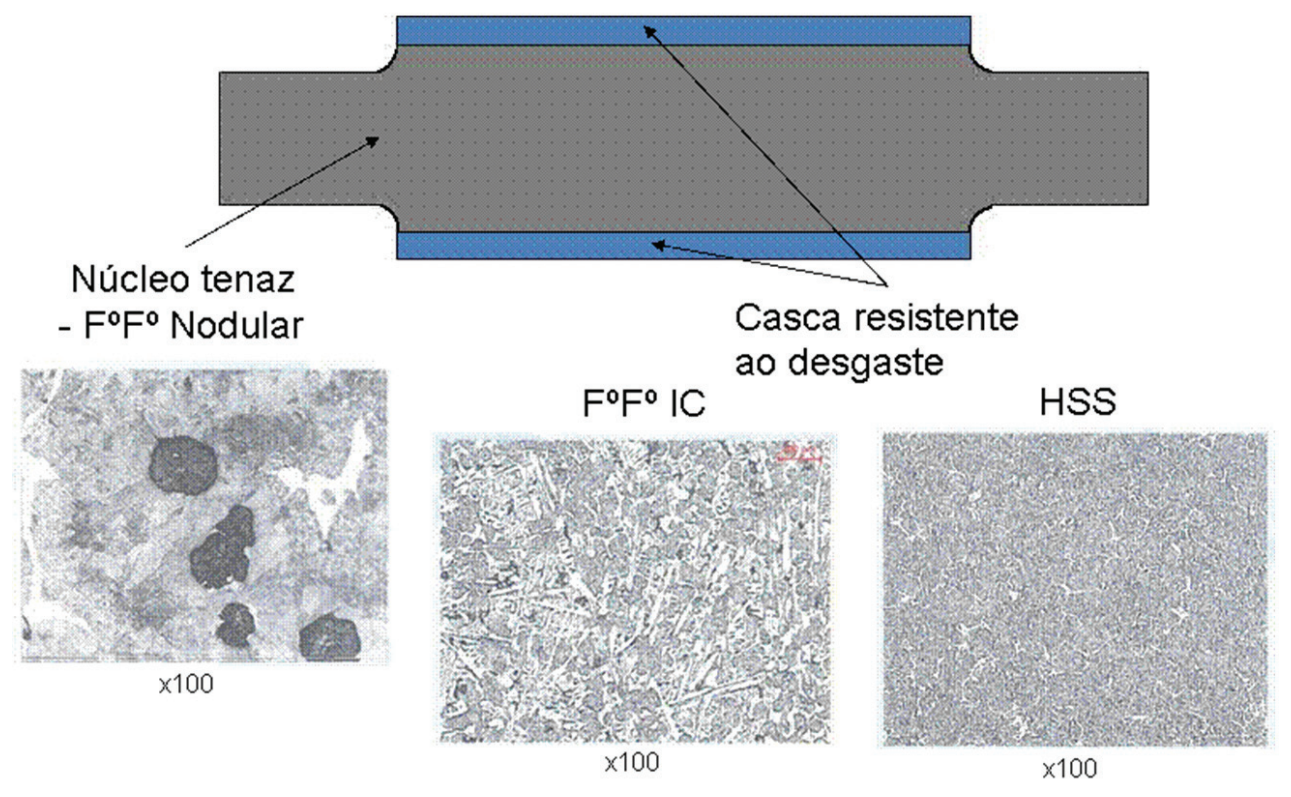

Figura I. Constituição básica de um cilindro de trabalho para laminação de tiras a quente. Detalhe da microestrutura do núcleo e da casca.

Tabela 2. Propriedades mecânicas dos cilindros ICDP e HSS (valores típicos). Limite de resistência à tração ( $\sigma \mathrm{t})$, limite de resistência à compressão $(\sigma c)$, módulo de elasticidade $(E)$, coeficiente de dilatação térmica linear $(\alpha)$, condutibilidade térmica $(K)$ e coeficiente de atrito $(\mu)$ [3]

\begin{tabular}{ccccccc}
\hline Tipo & $\sigma \mathbf{t}[\mathbf{M P a}]$ & $\sigma \mathbf{c}[\mathbf{M P a}]$ & $\mathbf{E}[\mathbf{G P a}]$ & $\alpha\left[\mathbf{x 1 0 ^ { - 6 } / \mathbf { K } ]}\right.$ & $\mathbf{K}[\mathbf{W} / \mathbf{m} \cdot \mathbf{K}]$ & $\boldsymbol{\mu}$ \\
\hline ICDP & $414-552$ & $1310-1724$ & $152-179$ & $10-13$ & $14-16$ & 0,30 \\
HSS & $689-896$ & $2551-3103$ & $234-248$ & $13-14$ & $18-20$ & 0,35 \\
\hline
\end{tabular}

tais como: expansão térmica linear, que fará com que o cilindro dilate mais e o atrito que aumentará a carga de laminação.

Outra característica muito importante do cilindro HSS é sua alta resistência ao desgaste devido a presença de carbonetos de elevada dureza, o que se mostra muito importante para cilindros laminadores. Esse tipo de material apresenta carbonetos do tipo $M C$ e $\mathrm{M}_{2} \mathrm{C}$, este último podendo ser decomposto à $\mathrm{M}_{6} \mathrm{C}$, por tratamento térmico. São cristalizados e precipitados de modo a apresentar propriedades resistentes ao trabalho a quente, muito importantes para esse tipo de laminação, conforme Cornélio [3].

\section{I.3.3 Condições operacionais dos cilindros de trabalho}

\section{I.3.3.I Aquecimento e resfriamento}

Os cilindros de trabalho sofrem, a cada rotação, um aquecimento devido ao contato com a tira e logo em seguida um resfriamento devido à ação dos sprays do sistema de refrigeração. Conforme apresentado por Ginzburg [4], a superfície do cilindro pode atingir aproximadamente $500^{\circ} \mathrm{C}$ no momento do contato com a tira, retornando à temperatura inicial quando passa pelo jato de água do sistema de resfriamento (Figura 2). Essa variação de temperatura diminui à medida que se aproxima do centro do cilindro. Esse efeito cíclico de aquecimento e resfriamento é o principal responsável pelo mecanismo de desgaste por fadiga térmica nos cilindros de trabalho.

\subsubsection{Deformações mecânicas}

Os cilindros de trabalho sofrem também deformações mecânicas importantes que merecem ser comentadas. A flexão ocorre devido às altas cargas de laminação aplicadas nas extremidades dos cilindros de encosto que por sua vez são transmitidas para os cilindros de trabalho. Hoje em dia, a maioria dos laminadores de tiras a quente possui sistema de contra flexão (work roll bending) para reduzir a flexão dos mesmos, evitando assim problemas de ondulação nas bordas da tira.

Os cilindros de trabalho estão sujeitos também ao achatamento (flattening). Essa deformação nada mais é do que a deformação elástica dos cilindros devido à pressão envolvida entre as regiões de contato entre cilindro de encosto-cilindro de trabalho e cilindro de trabalho-tira.

Outro tipo de deformação sofrida pelos cilindros é a dilatação térmica que acontece ao longo de sua campanha no laminador, devido ao aquecimento acumulativo, principalmente na região central da sua mesa onde se dá o maior aporte térmico. A dilatação térmica dos 


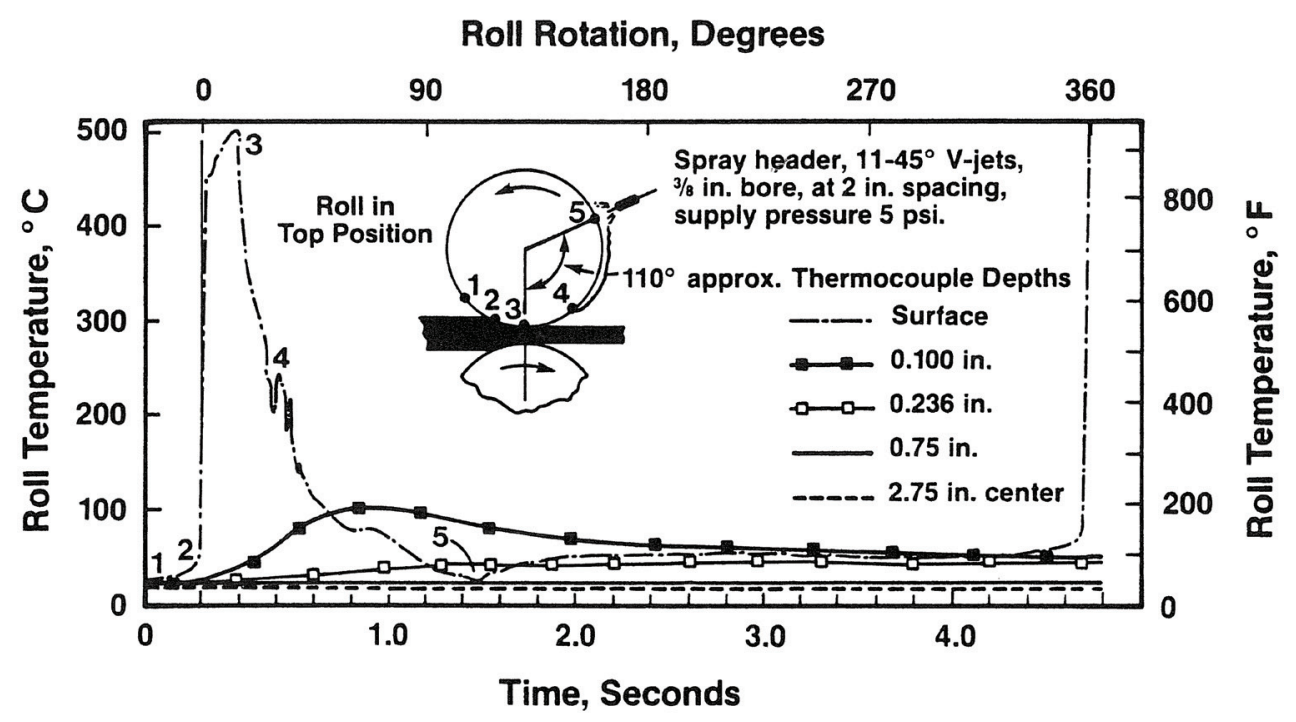

Figura 2. Variação da temperatura do cilindro de trabalho, em diferentes posições da superfície, durante a primeira revolução. [4]

cilindros de trabalho interfere diretamente no coroamento final da tira no sentido de reduzi-lo, tira após tira. Esse efeito torna-se mais evidente em laminadores que não possuem dispositivos de correção do perfil da tira do tipo CVC (continuously variable crown) como é o caso do Steckel da Aperam.

Finalmente, em sentido oposto à dilatação térmica, temos o fenômeno de desgaste dos cilindros de trabalho. Esse é o principal motivo das trocas dos mesmos, pois cada tira laminada aprofunda o canal de desgaste até atingir um limite no qual não se consegue continuar a laminação sem que ocorra comprometimento da forma da tira.

\section{I.3.3.3 Acidentes durante a laminação}

Além de todos os fenômenos sofridos pelos cilindros de trabalho, descritos acima, eles também são submetidos às condições severas durante sua operação. Tais condições anormais são classificadas como acidentes e que podem variar desde uma ponta fria que pode levar a uma simples marca em sua superfície até um rompimento de tira seguido de colamento em toda a sua mesa. Nestes casos de acidentes mais graves há inevitavelmente ocorrência de trincas profundas, levando a grandes perdas de camada útil do cilindro.

\section{MATERIAIS E MÉTODOS}

\section{I Medidas Implantadas}

Como os cilindros HSS apresentam características diferentes em relação ao cilindro ICDP foram necessários ajustes no processo, os quais são descritos a seguir.

\section{I.I Melhoria do sistema de refrigeração dos cilindros}

O sistema de refrigeração do Steckel vem sofrendo melhorias desde 200 I, com o advento do projeto "Bobina Pesada" o que permitiu aumentar o peso máximo da bobina laminada a quente de 13 t para 25 t. Entretanto, em janeiro de 2007, foi implantada uma mudança nesse sistema que trouxe um resultado extraordinário em termos de distribuição da temperatura ao longo da mesa do cilindro. Para tanto, os chuveiros (headers) passaram a contar com seis zonas ao invés de apenas duas (Figura 3a). Dessa forma, a água de refrigeração é melhor distribuída ao longo da mesa do cilindro, levando-se em conta a largura do material laminado. Como resultado, o perfil de temperatura do cilindro ficou mais uniforme e em um patamar mais baixo (Figura 3b). Essa mudança foi fundamental para a aplicação dos cilindros HSS, já que esse tipo de material possui um coeficiente de expansão linear maior se comparado ao ferro fundido indefinido, conforme mostrado na Tabela 2.

\section{I.2 Ajuste do coroamento mecânico dos cilindros}

Mesmo com a melhoria do sistema de refrigeração implantada a partir de 2007, conforme descrito no item anterior, foram necessários alguns ajustes de coroamento mecânico dos cilindros. Os aços elétricos de grão orientado (GO) e grão não orientado (GNO) tiveram o coroamento mecânico diminuído para garantir o coroamento da tira dentro da faixa especificada (Tabela 3). Isso porque os aços elétricos são os aços que oferecem maior aporte de calor aos cilindros de trabalho. Especificamente no GO pela elevada temperatura de laminação e no GNO pelo baixo intervalo entre tiras. 

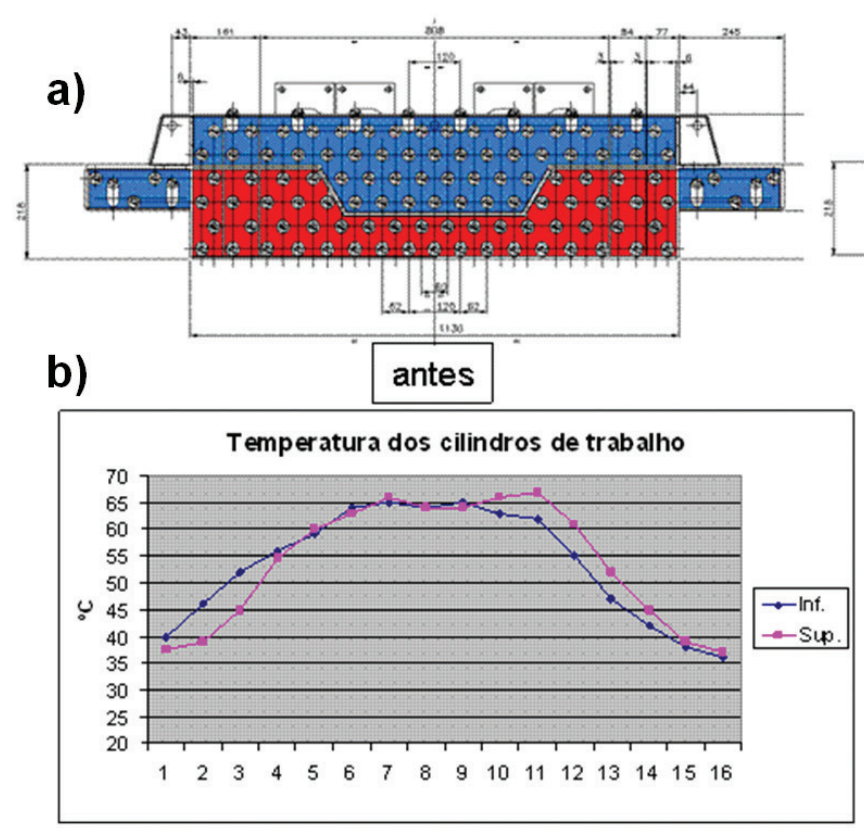

Figura 3. (a) chuveiro de refrigeração dos cilindros de trabalho (antes - 2 zonas; depois 6 zonas); e (b) perfil de temperatura ao longo da mesa do cilindro de trabalho após campanha de laminação de aço inox 304, antes e após as modificações dos chuveiros.

Tabela 3. Coroa mecânica para cilindros de $\mathrm{F}^{\circ} \mathrm{F}^{\circ}$ e HSS

\begin{tabular}{ccc}
\hline Aço & $\begin{array}{c}\text { Coroa mecânica }-\mathbf{F}^{\circ} \mathrm{F}^{\circ} \\
(\mathbf{m m})\end{array}$ & $\begin{array}{c}\text { Coroa mecânica - HSS } \\
(\mathbf{m m})\end{array}$ \\
\hline GNO & $-0,04$ & $-0,12$ \\
GO & $-0,15$ & $-0,20$ \\
\hline
\end{tabular}

\section{I.3 Ajuste do modelo matemático de desgaste}

O modelo matemático, responsável pelo cálculo do desgaste dos cilindros de trabalho, foi outro item que demandou ajustes. $O$ coeficiente de desgaste $K$ para os cilindros HSS foi obtido pelo cálculo reverso da Equação I. Para tanto, utilizaram-se os valores reais de desgaste, medidos antes de efetuar a retificação dos cilindros, a média dos valores de carga de laminação em cada passe, comprimento laminado, o raio do cilindro e a largura da tira laminada.

$$
\text { Desgaste }=\mathrm{K} \times \sum_{\mathrm{i}=1}^{\mathrm{n}} \frac{\mathrm{F}_{\mathrm{i}}}{2 \pi \mathrm{RW}} \times \alpha(\mathrm{j})
$$

onde: $i=$ número passe de laminação; $K=$ coeficiente de desgaste; $F_{\mathrm{i}}=$ força de laminação; $L_{\mathrm{i}}=$ comprimento laminado; $R=$ raio do cilindro; $W_{\mathrm{i}}=$ largura da tira; $n=$ número total de passes; e $\alpha(j)=$ coef. de forma por segmento.

\section{I.4 Lubrificação dos cilindros de trabalho}

A lubrificação dos cilindros de laminação tem como objetivo reduzir $\circ$ atrito entre $\circ$ cilindro e $\circ$ material laminado, na região do arco de contato. Logo, o principal
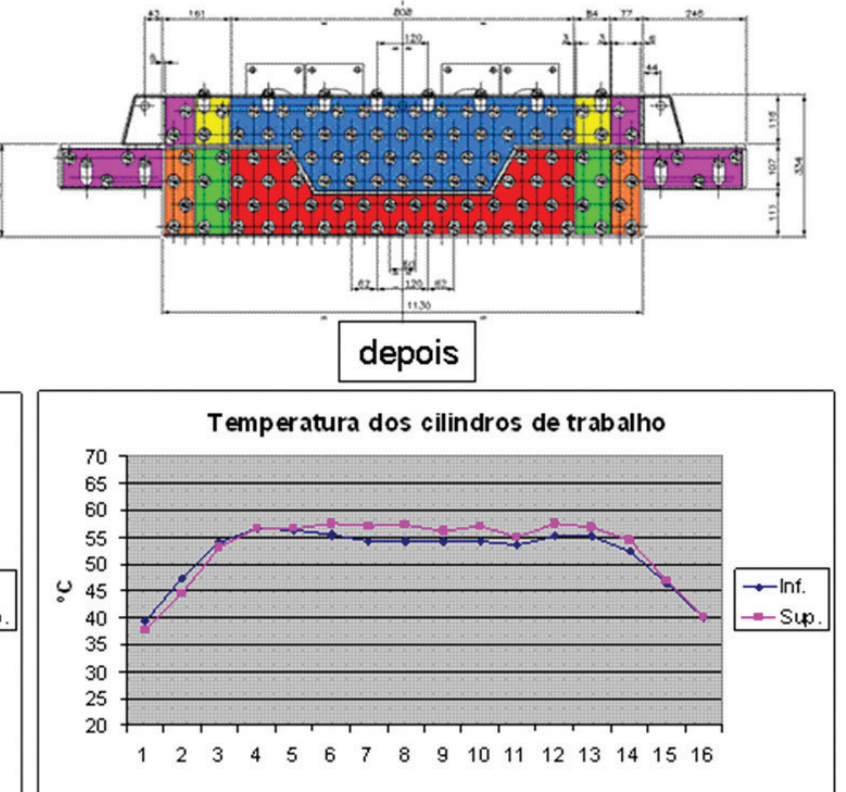

efeito esperado com esse procedimento é a redução do desgaste dos cilindros, aumentando assim o tamanho das campanhas. Outros benefícios decorrentes de um menor atrito são redução das cargas de laminação juntamente com a redução do consumo de energia elétrica. No caso de se utilizar cilindros HSS, a lubrificação dos mesmos torna-se ainda mais desejada, tendo em vista que o coeficiente de atrito desse tipo de cilindro é maior do que os de ferro fundido indefinido, conforme mostrado na Tabela 2.

\subsubsection{Adequação e sistematização dos testes não destrutivos}

A oficina de cilindros da laminação a quente há muitos anos realiza os testes não destrutivos, durante o acompanhamento da vida útil dos cilindros. Os principais testes realizados são: corrente parasita (eddy current), ultrassom, líquido penetrante e medição de dureza. Estes testes são fundamentais na detecção prematura e prevenção de defeitos que podem ou não ser originados durante a laminação. Mas para a aplicação dos cilindros HSS, esses testes passaram primeiramente por um processo de adequação, seguido de uma sistematização, a saber:

- Eddy Current: inspeção continuou a ser realizada $100 \%$ dos cilindros logo após o procedimento de retificação. Toda trinca detectada nos cilindro HSS passou a ser removida totalmente (Figura 4). Diferentemente dos cilindros ICDP que em determinadas situações admite-se liberar o cilindro com um determinado nível de trinca;

- Ultrassom: inspeção com ultrassom pelo menos três vezes durante a vida do cilindro (início, meio 


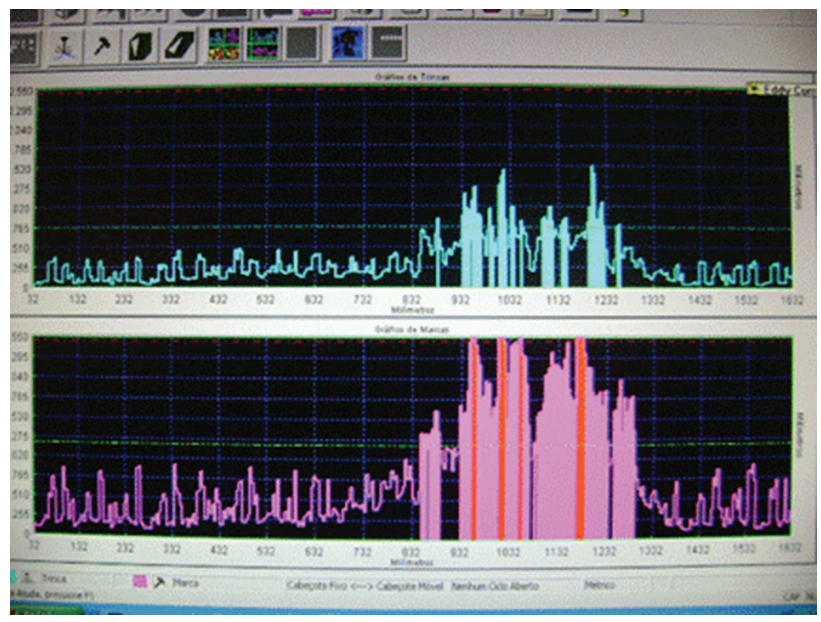

Figura 4. Tela do Eddy Current indicando ocorrência de trincas/marcas.

e fim), independentemente do tipo do cilindro. Inspeção em $100 \%$ dos cilindros acidentados no laminador, do tipo rompimento de tira, marcas fortes decorrentes de recuperações ou sucateamento de tira. Finalmente, inspeção após a remoção de trincas localizadas (Figura 5);

- Líquido Penetrante: esse teste é coadjuvante na caracterização do tipo de trinca e no processo de sua remoção.

A realização dos testes descritos acima, de forma sistemática, tem contribuído sobremaneira na prevenção de grandes quebras de cilindros durante a laminação. Principalmente nos cilindros HSS, por serem menos resistentes à ocorrência de trincas e também por apresentarem uma região de interface casca/núcleo mais crítica ao surgimento de defeitos de fabricação, tais como: segregação, porosidades etc.

\subsubsection{Treinamentos}

Ao longo do desenvolvimento da aplicação dos cilindros HSS no laminador Steckel, foram ministrados alguns treinamentos, que com certeza, contribuíram para consolidar esse novo processo. Dentre eles podemos citar: "Cilindros HSS" e "Detecção de defeitos em cilindros por Ultrassom”, ministrados pela Villares Rolls; "Critérios para remoção de trincas" e "Cuidados operacionais na utilização de cilindros HSS" ministrados pelos próprios engenheiros da Aperam.

\section{RESULTADOS}

\section{I Desempenho dos Cilindros de Trabalho}

O volume de cilindros HSS na família do Steckel começou com um par e foi aumentando gradativamente até atingir $50 \%$ a partir de 2009 , o que representa apro-

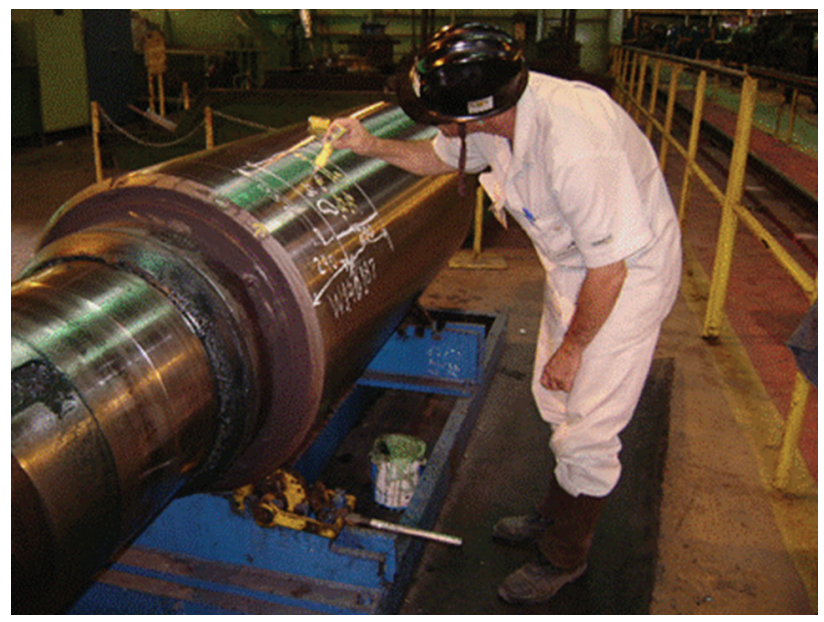

Figura 5. Mapeamento de defeito após ensaio por ultrassom.

ximadamente 14 cilindros. A Figura 6 mostra a evolução do desempenho médio anual dos cilindros de trabalho do Steckel, desde o início do seu desenvolvimento em 2005. O desempenho médio anual é obtido dividindo-se o total produzido pelo consumo total de cilindros no mesmo período.

Nota-se uma melhoria progressiva de desempenho, a partir de 2007. Isso é explicado pelo fato dos cilindros HSS apresentarem uma maior resistência ao desgaste, em relação aos cilindros ICDP.

\subsection{Número de Trocas de Cilindros de Trabalho}

Uma consequência imediata, quando se tem uma melhoria do desempenho dos cilindros de trabalho, é a redução do número de trocas do conjunto de cilindros (superior e inferior). O gráfico da Figura 7 mostra que nos últimos 5 anos a quantidade de trocas de cilindros de trabalho no laminador Steckel caiu pela metade. Isso significa 3 trocas a menos por cada 1.000 t laminadas.

Considerando-se uma produção anual em torno de 760 kt e uma média de 4,6 minutos por troca, teremos um aumento de disponibilidade de laminação de 175 horas. Isso representa uma capacidade de aumento de oferta de $15 \mathrm{kt} / \mathrm{ano}$ de bobinas a quente.

Em 2009, não houve redução do número de trocas de cilindros de trabalho, visto que a produção foi completamente atípica, em função da crise financeira mundial. Podemos citar algumas condições que favoreceram a troca prematura dos cilindros, tais como: campanhas pequenas acarretando mudanças de setup, aumento da laminação de materiais de espessura fina e de maior complexidade, muitas paradas de linha por falta de pedidos etc.

\subsection{Qualidade Superficial da Tira}

Durante o desenvolvimento da aplicação dos cilindros HSS ocorreram basicamente dois problemas que 


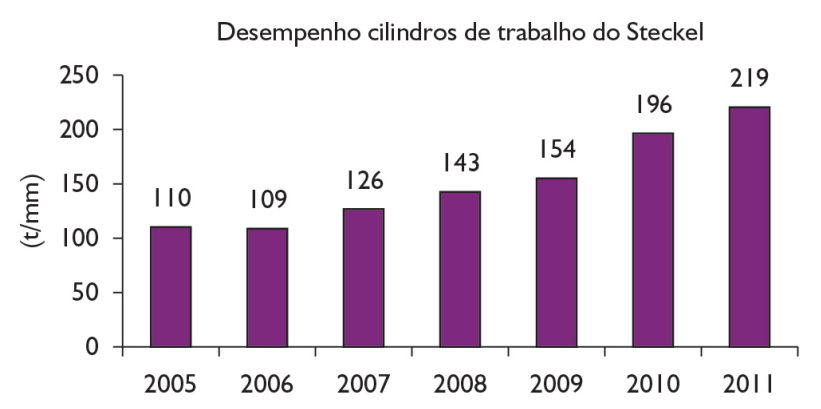

Figura 6. Evolução do desempenho médio anual dos cilindros de trabalho do Steckel.

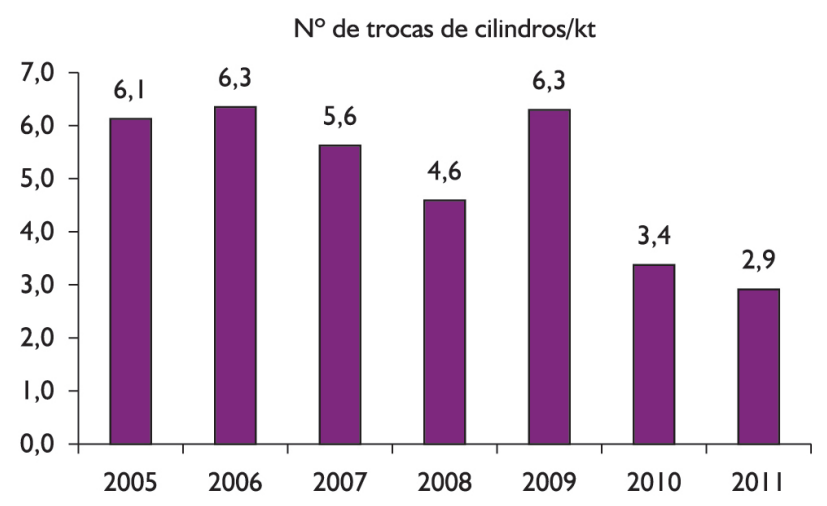

Figura 7. Evolução do número de trocas de cilindros por mil toneladas laminadas.

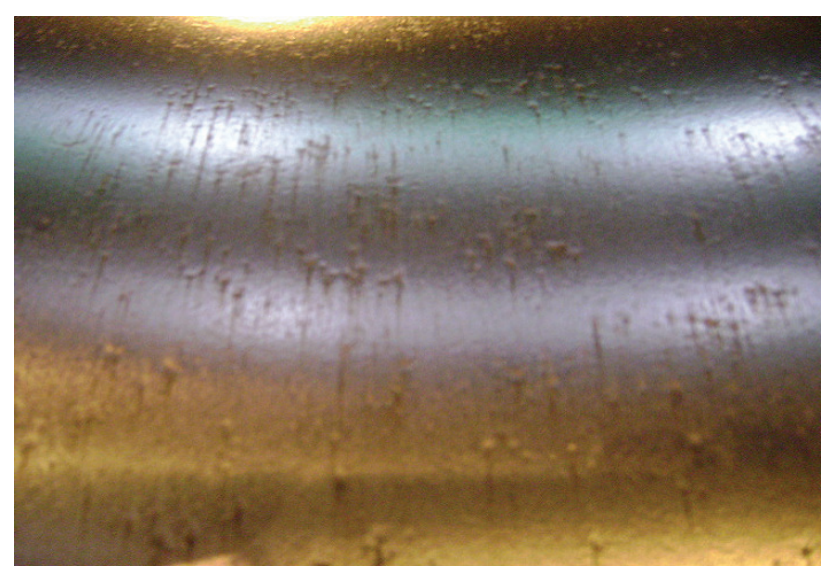

Figura 8. Defeito superficial apresentado por alguns cilindros HSS.

afetaram a qualidade da tira. $O$ primeiro foi apelidado de "catapora" devido às pequenas cavidades apresentadas ao longo da mesa do cilindro (Figura 8), que por sua vez imprimia marcas em alto relevo na tira. Este defeito foi identificado em apenas quatro cilindros e a causa identificada como casca fina. Em outras palavras, a espessura da casca estava insuficiente nesses cilindros.

Outro problema que também afetou a qualidade superficial da tira foi o defeito caracterizado como mancha ou mapa (Figura 9). Esse defeito foi identificado logo nas primeiras montagens dos cilindros de um deter-

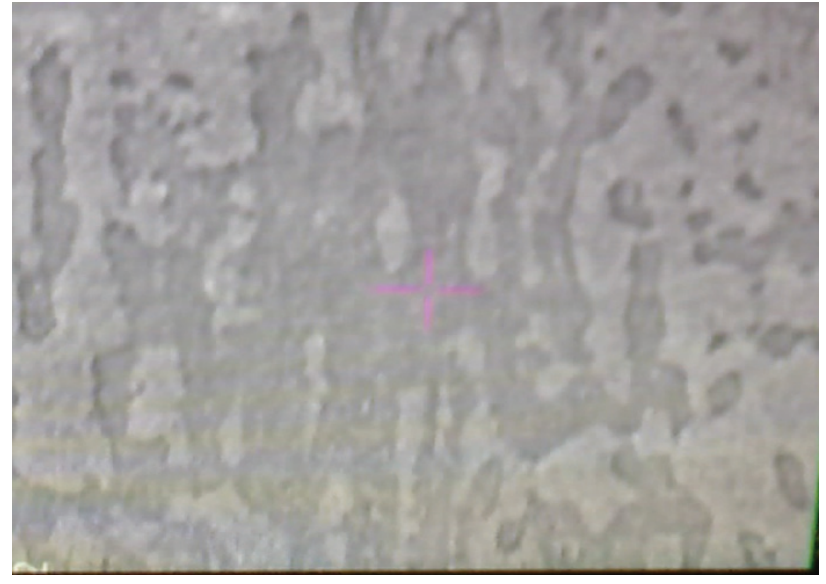

Figura 9. Imagem do defeito "mancha" em uma tira após o último passe de laminação no Steckel.

minado fornecedor. Investigações feitas pelo fabricante constataram que esse tipo de defeito estava relacionado com o nível excessivo de vibração da centrífuga, durante o processo de vazamento do material da casca. Medidas foram tomadas no sentido de reduzir/eliminar essas vibrações no processo de fabricação nas remessas seguintes. Por se tratar de um defeito bastante leve, os cilindros que apresentaram esse tipo de defeito não foram sucateados, mas foram impedidos de laminar os aços inoxidáveis ferríticos por serem mais macios e terem maior exigência de qualidade superficial.

\section{CONCLUSÃO}

Hoje, a Aperam detém o completo domínio na utilização de cilindros HSS em Laminador Steckel;

A Aperam está na vanguarda quanto à utilização desse tipo de cilindro, quebrando o paradigma de que não é viável utilizar cilindros HSS em cadeiras acabadoras.

O aumento progressivo da participação dos cilindros HSS em detrimento aos cilindros de ferro fundido (ICDP), nas famílias de cilindros de trabalho dos laminadores Rougher e Steckel é altamente recomendável. A Laminação a Quente da Aperam - Timóteo passou a operar, a partir de $2013 \mathrm{com} 100 \%$ de cilindros de trabalho em HSS, nos Laminadores Rougher e Steckel.

\section{Agradecimentos}

Agradecemos a Villares Rolls pelos treinamentos ministrados sobre "Detecção de defeitos em cilindros de laminação por ultrassom" e "Cilindros HSS: Processo de fabricação, características, aplicações e cuidados na utilização". 


\section{REFERÊNCIAS}

I Barbosa AA. Análise do desgaste dos cilindros de trabalho de um laminador de tiras a quente reversível tipo Steckel [dissertação de mestrado]. Belo Horizonte: Escola de Engenharia, Universidade Federal de Minas Gerais; 2004.

2 Sinnaeve MHSS. Work rolls for hot mill finishing stands: keys to success. In: AISTech 2010 Conference Proceedings; 2010; Pittsburgh, EUA. Warrendale: AIST; 20I0. v. 2, p. 279-92.

3 Cornélio GT. Caracterização de materiais utilizados na fabricação de cilindros de laminação submetidos ao desgaste abrasivo [dissertação de mestrado]. Guaratinguetá: Faculdade de Engenharia de Guaratinguetá; 2006.

4 Ginzburg VB. Profile and flatness of flat rolled products - Rolling mill technology. 3rd ed. Pittsburgh: Robert Ballas United Engineering Inc.; 1994.

Recebido em: 07/05/2013

Aceito em: 12/12/2013 